\title{
Influence of naturally occurring antioxidants on magnetic nanoparticles: Risks, benefits, and possible therapeutic applications *
}

\author{
Štefan Durdík ${ }^{1,2}$, Hanka Vrbovská3 ${ }^{3}$ Adam Olas ${ }^{3}$ and Melánia Babincová ${ }^{3}$ \\ ${ }^{1}$ St. Elizabeth Cancer Institute, Bratislava, Slovak Republic \\ ${ }^{2}$ Department of Oncological Surgery, Faculty of Medicine, Comenius University, Bratislava, Slovak Republic \\ ${ }^{3}$ Department of Nuclear Physics and Biophysics, Faculty of Mathematics, Physics, and Informatics, Comenius University, \\ Bratislava, Slovak Republic
}

\begin{abstract}
We have studied interaction of well known antioxidant L-ascorbic acid with magnetic nanoparticles containing insoluble Fe(III) in their core. In analogy with ferritin, mobilization of iron in the form of water soluble Fe(II) was observed, especially pronounced at higher temperatures. In the presence of hydrogen peroxide cytotoxic hydroxyl radicals are produced. These results suggest possible harmful effects of widely used magnetic nanoparticles as a MRI contrast agents in combination with overload of organism with ascorbic acid in some specific conditions, like fever of patient. On the other hand combination of magnetic nanoparticles and ascorbic acid may be used for a cancer therapy using alternating magnetic field for the release of Fe(II) via Néel relaxation of magnetic moment of used nanoparticles. We have further found that lipoic acid is an efficient antioxidant scavenging hydroxyl radicals produced by Fenton reaction from $\mathrm{Fe}(\mathrm{II})$.
\end{abstract}

Key words: Magnetic nanoparticles - Toxicity - Oxidative stress - Antioxidants - Cancer therapy

\section{Introduction}

Multifunctional magnetic nanoparticles have diverse potential biomedical applications, such as cell separation, drug targeting, electromagnetic hyperthermia, magnetic resonance contrast enhancement (Harivardhan et al. 2012). For the first time protein ferritin containing $4 \mathrm{~nm}$ large magnetic nanoparticle was prepared by V. Laufberger (Laufberger 1937). Ferritin besides its key role in iron body metabolism (Kohgo et al. 2008) can be used as a magnetic nanoparticle for multifold purposes. Let us mention pathogenesis of Alzheimer (Pankhurst et al. 2008) and Parkinson diseases (Babincova and Babinec 2005), magnetic cell separation (Kronick and Gilpin 1986), magnetic drug targeting (Sim-

Correspondence to: Melánia Babincová, Department of Nuclear Physics and Biophysics, Faculty of Mathematics, Physics, and Informatics, Comenius University, Mlynská dolina F1, 84248 Bratislava, Slovak Republic

E-mail: babincova@fmph.uniba.sk

* This article was presented at the $5^{\text {th }}$ Slovak Biophysical Symposium, organized by The Slovak Biophysical Society in Bratislava, March 19-21, 2012 sek and Akif Kilic 2005), MRI contrast agents (Gilad et al. 2007), electromagnetic hyperthermia (Babincova et al. 2000), ultrasensitive diagnosis (Lee e al. 2007), and macroscopic quantum tunnelling (Gider et al. 1995).

Iron is an essential nutrient for mammals and most life forms and iron oxide nanoparticles were generally assumed to be safe, however, this type of nanoparticles can be toxic in some cell types and their nano-toxicity in yet another type of cell suggests that these particles may not be as safe as we had once thought. Exposure to magnetic nanoparticles could potentially lead to toxic side effects such as membrane leakage of lactate dehydrogenase, impaired mitochondrial function, inflammation, formation of apoptotic bodies, chromosome condensation, generation of reactive oxygen species (ROS) and DNA damage (Pickard and Chari 2010; Singh et al. 2010; Pinkernelle et al. 2012).

For the biocompatibility, as well as stability of iron magnetic core are magnetic nanoparticles covered by protecting sheet from lipids, fatty acids, saccharides, and other polymers. Although in nanoparticles the iron is in the "safe" - insoluble $\mathrm{Fe}^{3+}$ oxidation state as in the ferritin, it is always possible that some compounds can reduce this form of iron into the $\mathrm{Fe}^{2+}$ state, which is soluble, and is a risk for the or- 
ganism (Herbert et al. 1996). Our aim is to study interaction of magnetic nanoparticles with antioxidants. Paradoxically best known antioxidant - ascorbic acid can reduce iron and form toxic free radicals via the Fenton reaction, which can lead to the oxidative stress (Fenton 1894; Winterbourn 1995). Ascorbic acid $\left(\mathrm{H}_{2} \mathrm{Asc}\right)$ is considered the main water-soluble antioxidant in blood plasma (Halliwell 1996; Herbert et al. 1996). The importance of $\mathrm{H}_{2} \mathrm{Asc}$ as an antioxidant is due to the low reduction potential of the ascorbyl radical/ascorbate anion couple, serving as the terminal reducing agent in the oxidizing free radical chain reactions in biological systems. $\mathrm{H}_{2}$ Asc readily scavenges reactive oxygen and nitrogen species and thereby protects substrates from oxidative damage. Ascorbyl radical with high stability and low reactivity is formed during this reaction. $\mathrm{H}_{2} \mathrm{Asc}$ reduces superoxide anion radical to hydrogen peroxide, rapidly reacts with hydroxyl radical and converts it into water.

Our aim is to investigate the interaction of ascorbic acid with magnetic nanoparticles, which have structure similar to ferritin, and therefore similar behaviour can be expected.

\section{Material and Methods}

\section{Chemicals}

Solution of $0.5 \mathrm{mM}$ L-ascorbic acid and 0-12 mM lipoic acid (1,2-dithiolane-3-pentanoic acid) from Sigma Aldrich (St. Louis, MO, USA) was freshly prepared for each experiment. The biocompatible colloidal suspension of magnetic nanoparticles (fluidMAG-D) used in experiments with concentration $0.3 \mathrm{mg} / \mathrm{ml}$ was produced by Chemicell

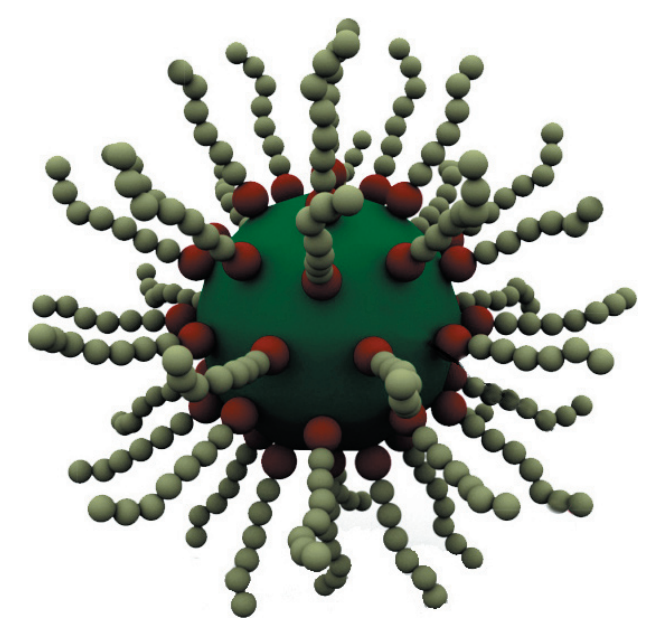

Figure 1. General structure of magnetic nanoparticle consists magnetic core (e.g. magnetite or maghemite) stabilized on the surface by polymer (e.g. polysaccharide).

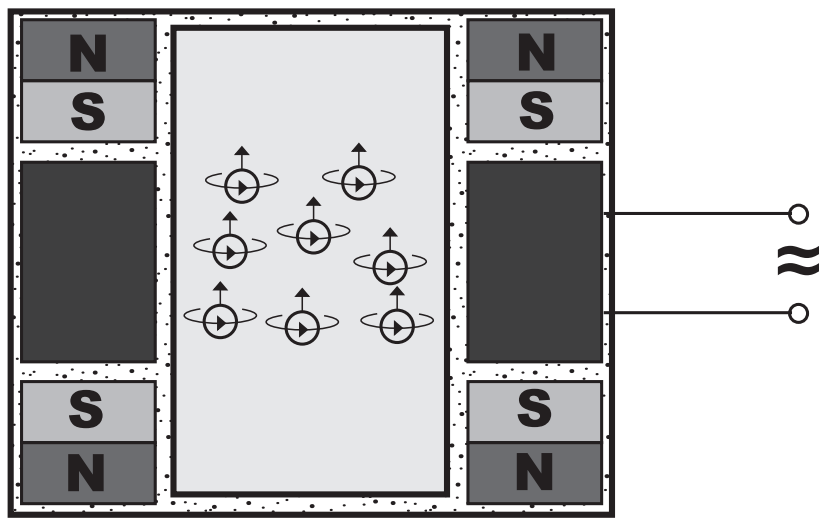

Figure 2. Alternating electromagnetic field induce rotation of magnetic nanoparticles (more details in the text).

GmbH (Berlin, Germany; German patent application no. 19624426.9) by wet chemical methods from iron oxides and hydroxides to produce special multidomain particles. These nanoparticles are covered with hydrophilic starch polymers coupled with end standing hydroxyl functional group (Fig. 1). These magnetic nanoparticles were primarily developed for MRI diagnostic.

\section{Monitoring reaction between ascorbic acid and magnetic nanoparticles}

For spectrofotometric and kinetic experiments was used spectrophotometer UVmini 1240 (Shimadzu, Kyoto, Japan). Experiments were performed by varying the initial temperature. Required temperatures of samples were kept by thermostatic bath $\left( \pm 0.1^{\circ} \mathrm{C}\right)$. Each of the kinetic runs was started by mixing solutions of ascorbic acid with magnetic nanoparticles $(1: 1)$ and the resulting solution complex was subjected to the spectral studies. The released iron was monitored by measuring the increase in absorbance at $530 \mathrm{~nm}$ due to the chelation of $\mathrm{Fe}^{2+}$ by $1.0 \mathrm{mM}$ bathophenanthroline sulfonate $\left(\varepsilon_{530}=22.14 \mathrm{~cm}^{-1} \cdot \mathrm{mM}^{-1}\right)$.

\section{Setup for application of electromagnetic hyperthermia}

When magnetic nanoparticles are irradiated with an alternating electromagnetic field, they rotate and are therefore heated due to energy dissipation in viscous fluid (Fig. 2). This heating was performed using a $3 \mathrm{MHz}$ radiofrequency generator (GV6A, ZEZ Rychnov, Czech Republic) with a power dissipation of $6 \mathrm{~kW}$. The coil-shaped and water-cooled antenna was made of 3 copper windings with a diameter of $14.5 \mathrm{~cm}$, connected to a water-cooled resonance circuit which produced the electromagnetic field. The system created a magnetic field with induction of $1.5 \mathrm{mT}$ in the centre of the coil, where the sample was inserted. The temperature 
of the suspension was measured by contactless infrared thermometer.

\section{Determination of Klein peroxidation index}

Peroxidation was initiated by Fenton oxidative system $\mathrm{H}_{2} \mathrm{O}_{2} / \mathrm{FeSO}_{4}$. Liposome samples were incubated with lipoic acid or phosphate buffer (control) at $37^{\circ} \mathrm{C}$ for $30 \mathrm{~min}$, then incubated with $\mathrm{H}_{2} \mathrm{O}_{2}(10 \mathrm{mM})$ and $\mathrm{FeSO}_{4}(80 \mu \mathrm{M})$ at $37^{\circ} \mathrm{C}$ for $60 \mathrm{~min}$. Absorption spectra of the conjugated dienes were recorded in the wavelength range 190-340 nm using a UV MINI 1240 UV-VIS spectrophotometer (Shimadzu, Kyoto, Japan). The increase of the absorption at $233 \mathrm{~nm}$ was considered as an evidence of the formation of the conjugated dienes (Babincová et al. 1999; Sivoňová et al. 2006), and the oxidation index was calculated from the ratio of the absorbance values $\left(\mathrm{A}_{233} / \mathrm{A}_{215}\right)$.

\section{Results and Discussion}

Although beneficial effects of ascorbic acid are almost universally recognized and were studied in details (Ďuračková 2003), it should be stressed that besides its antioxidant activity when reduces oxidizing substances such as hydrogen peroxide, it can also reduce metal ions which leads to the generation of cytotoxic free radicals through the Fenton reaction (Fenton 1894; Winterbourn 1995). Upon their reduction by ascorbate

$$
\mathrm{H}_{2} \mathrm{Asc} \rightarrow \mathrm{HAsc}^{-}+\mathrm{H}^{+}
$$

these metal ions can react with hydrogen peroxide

$$
\mathrm{AscH}^{-}+\mathrm{Fe}^{3+} \rightarrow \mathrm{Asc}^{\bullet-}+\mathrm{Fe}^{2+}+\mathrm{H}^{+}
$$

or lipid hydroperoxides

$$
\mathrm{H}_{2} \mathrm{O}_{2}+\mathrm{Fe}^{2+} \rightarrow \mathrm{HO}^{\bullet}+\mathrm{Fe}^{3+}+\mathrm{HO}^{-}
$$

to produce either hydroxyl radicals or lipid alkoxyl radicals:

$$
\mathrm{LOOH}+\mathrm{Fe}^{2+} \rightarrow \mathrm{LO}^{\bullet}+\mathrm{Fe}^{3+}+\mathrm{HO}^{-}
$$

The metal ion in this reaction can be reduced, oxidized, and then again reduced in a process called redox cycling that can generate reactive oxygen species. The reactions between ascorbate and transition metals are thought to be responsible for the pro-oxidant and cytotoxic properties of ascorbate.

In these experiments we have investigated capability of ascorbic acid for reduction of $\mathrm{Fe}(\mathrm{III})$ to $\mathrm{Fe}(\mathrm{II})$ during inter-

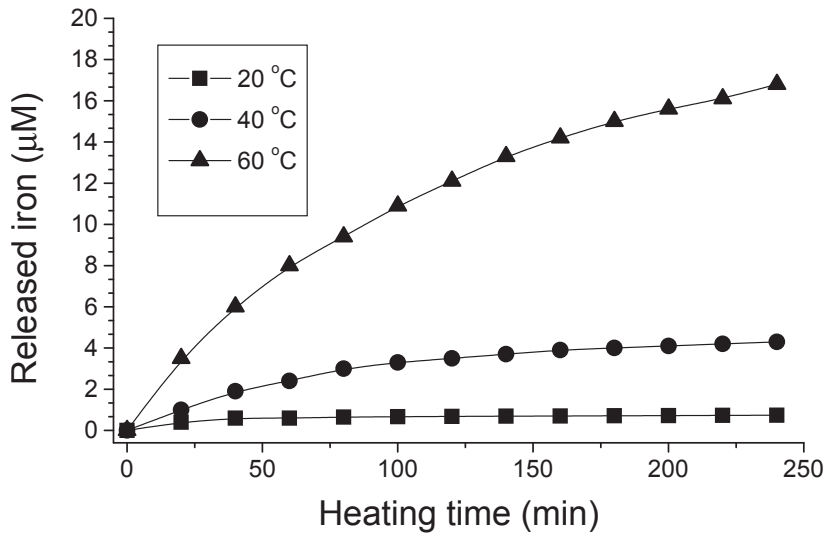

Figure 3. Time dependence of ascorbic acid-induced iron release at various temperatures.

action. The oxidation of $\mathrm{H}_{2} \mathrm{Asc}$ involves electron transfer from ascorbic acid to magnetic nanoparticles. $\mathrm{H}_{2} \mathrm{Asc}$ first dissociated to $\mathrm{HAsc}^{-}$and release a proton. Iron in magnetic nanoparticles reacts with $\mathrm{HAsc}^{-}$involving an outer sphere one-electron transfer from $\mathrm{HAsc}^{-}$to magnetic nanoparticles to form an intermediate reduced species $\left[\mathrm{Fe}_{3} \mathrm{O}_{4}\right]^{-}$and ascorbate radical HAsc ${ }^{\circ}$ (Shukla and Pant 2003). A rapid electron transfer from $\mathrm{HAsc}{ }^{\circ}$ to $\left[\mathrm{Fe}_{3} \mathrm{O}_{4}\right]^{-}$gives the reduced magnetic nanoparticles $\left[\mathrm{Fe}_{3} \mathrm{O}_{2}(\mathrm{OH})_{2}\right]$ and dehydroascorbic acid Asc. Time dependence of iron release at various temperatures is shown in Fig. 3. We have found that at physiological temperatures the reduction and release of $\mathrm{Fe}^{2+}$ from magnetic nanoparticles using ascorbic acid with the highest possible concentration $(0.5 \mathrm{mM})$ which can be achieved by nutrition or supplements, is almost negligible and the amount of released iron is substantially increased at higher temperatures. These results suggest possible harmful effects of widely used magnetic nanoparticles as a MRI contrast agents in combination with overload of organism with ascorbic acid in some specific conditions, like fever of patient.

As is clear from our results, higher doses of ascorbic acid when combined with application of magnetic nanostructures are a risk factor due to the possible oxidative cell injury. On the other hand, since e.g. neuroblastoma cells contain elevated iron levels (stored in ferritin) and produce high amounts of $\mathrm{H}_{2} \mathrm{O}_{2}$, conditions for pro-oxidative cell injury can be generated. And really by application of i.v. injection of pharmacologic doses (20 mM as compared with physiological blood plasma concentration of $6.5 \mu \mathrm{M}$, or highest possible blood concentration of $0.5 \mathrm{mM}$ when taken ascorbic acid orally) of ascorbic acid decreases the growth and weight of human, rat, and murine tumor xenografts in athymic, nude mice (Chen et al. 2008). This may be used as a new approach in cancer therapy of this hardly curable tumour, especially in combination with some cytostatic drugs (Takemura et al. 2010). 


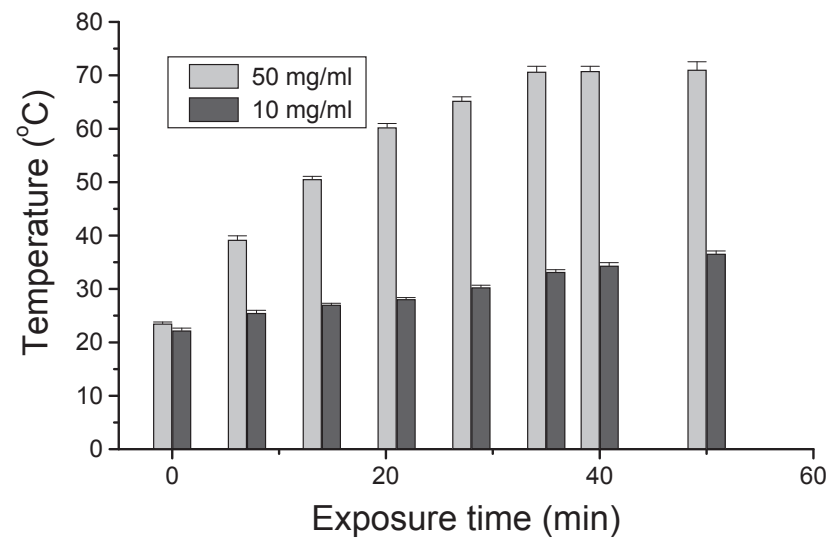

Figure 4. Heating of suspension of magnetic nanoparticles with two different concentrations in alternating magnetic field.

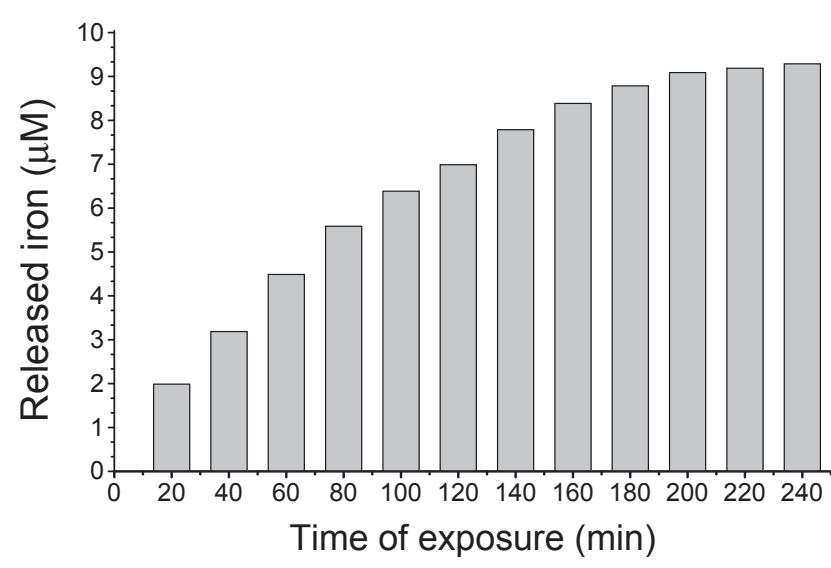

Figure 5. Ascorbic acid induced iron release from magnetic nanoparticles as a function of alternating magnetic field exposure.

Because the iron release is substantially increased at higher temperatures, we propose the following method of cancer therapy, inspired with above mentioned high concentration ascorbic acid administration:

1) Intravenous administration of ascorbic acid to achieve its high level especially near the cancerous tissue.

2) Intravenous administration of biocompatible magnetic nanoparticles and their targeting to the tumour site using high-gradient external magnetic field.

3) Heating of magnetic nanoparticles in an alternating magnetic field.

The feasibility of the first step has been shown in the recent studies of ascorbic acid mediated cancer therapy, when intravenous application of even $70 \mathrm{~g}$ ascorbic acid is commonly used. The second step, magnetic targeting to the tumour site is also common today (Babincová et al. 2001) and can be easily checked using MRI, because magnetic particles are widely used as a contrast agent (e.g. FDA approved Resovist and Ferridex). The third step, heating of magnetic nanoparticles, is also easily achieved using alternating magnetic field with frequency from $\mathrm{MHz}$ range (Babincová et al. 2004). Heating of fluidMAG-D nanoparticles for two different concentrations is shown in Fig. 4.

The influence of magnetic heating and ascorbic acid on the reduction and release of $\mathrm{Fe}$ (III) from magnetic nanoparticles is shown in Fig. 5. As can be seen, iron is massively released from magnetic nanoparticles. We have used concentration of magnetic nanoparticles only $0.3 \mathrm{mg} / \mathrm{ml}$, when macroscopic heating of the sample is almost negligible, but magnetic nanoparticles itself are via Néel relaxation heated to high temperatures (Babincová et al. 2004), which accelerate their reaction with ascorbic acid.

Because magnetic nanostructures are often stabilized by lipids, e.g. in magnetoliposomes, we have also proposed to use a-lipoic acid instead of ascorbic acid for their protection. Lipoic acid is one of the most effective antioxidant used in the prevention of Alzheimer disease, a progressive neurodegenerative disorder that destroys patient memory and cognition, and the $\mathrm{Fe}^{2+}$ ions are most harmful for neurons and glial cells (Biewenga et al. 1997). As is shown in Fig. 6, already at low concentrations of lipoic acid, peroxidation index is almost corresponding to the liposomes without oxidation (which equals to 0.53 ). Lipoic acid in vivo effects seems primarily to induce the oxidative stress response and scavenge free radicals (Bast and Haenen 2003). The reduced form of lipoic acid, dihydrolipoic acid, is probably the active compound responsible for these beneficial antioxidant effects.

Therefore its consumption before magnetic drug targeting, or during MRI scan with magnetic nanoparticles as a contrast agent, would be beneficial for protection of glial cells.

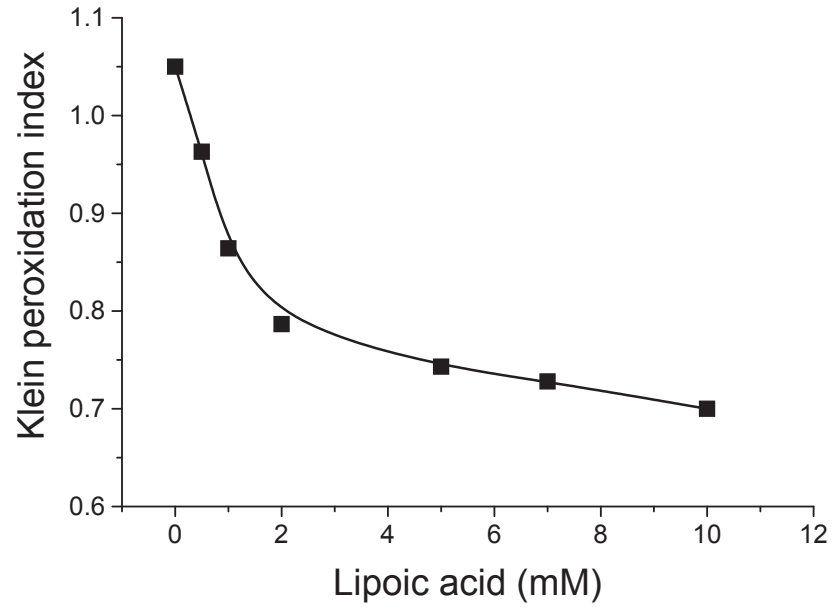

Figure 6. Dependence of Klein lipid peroxidation index on the concentration of lipoic acid. 
In conclusion, we can say that the interaction of antioxidants with magnetic nanostructures is an interesting field with many potential therapeutic applications.

Acknowledgement. This work was supported by the Slovak Grant Agency VEGA, project No. 1/0642/11.

\section{References}

Babincová M., Machová E., Kogan G. (1999): Carboxymethylated glucan inhibits lipid peroxidation in liposomes. Z. Naturforsch. C Biosci. 54, 1084-1088

Babincová M., Leszczynska D., Sourivong P., Babinec P. (2000): Selective treatment of neoplastic cells using ferritin-mediated electromagnetic hyperthermia. Med. Hypotheses 54, 177-179 http://dx.doi.org/10.1054/mehy.1999.0011

Babincová M., Babinec P., Bergemann C. (2001): High gradient magnetic capture of ferrofluid: Implication for drug targeting and tumor embolization. Z. Naturforsch. C: Biosci. 56, 909-911

Babincová M., Altanerová V., Altaner C, Čičmanec P., Babinec P. (2004): In vivo heating of magnetic nanoparticles in alternating magnetic field. Med. Phys. 31, 2219-2224 http://dx.doi.org/10.1118/1.1767101

Bast A., Haenen G. R. (2003): Lipoic acid: a multifunctional antioxidant. Biofactors 17, 207-213 http://dx.doi.org/10.1002/biof.5520170120

Biewenga G. P., Haenen G. R. M. M., Bast A. (1997): The pharmacology of the antioxidant lipoic acid. Gen. Pharmacol. 29, 315-331 http://dx.doi.org/10.1016/S0306-3623(96)00474-0

Chen Q., Espey M. G., Sun A. Y., Pooput C., Kirk K. L., Kirshna M. C., Khosh D. B., Drisko J., Levine M. (2008): Pharmacologic doses of ascorbate act as a prooxidant and decrease growth of aggressive tumor xenografts in mice. Proc. Natl. Acad. Sci. U.S.A. 105, 11105-11109 http://dx.doi.org/10.1073/pnas.08042261

Duračková Z. (2003): Free Radicals and Antioxidants in Medicine. Bratislava, Slovak Academic Press (in Slovak)

Fenton H. J. H. (1894): Oxidation of tartaric acid in the presence of iron. J. Chem. Soc. 65, 899-910 http://dx.doi.org/10.1039/ct8946500899

Gider S., Awschalom D. D., Douglas T., Mann S., Chaparala M. (1995): Classical and quantum magnetic phenomena in natural and artificial ferritin proteins. Science 268, 77-80 http://dx.doi.org/10.1126/science.7701343

Gilad A. A., Winnard P. T. Jr., van Zijl P. C. M., Bulte J. W. M. (2007): Developing MR reporter genes: Promises and pitfalls. NMR Biomed. 20, 275-290 http://dx.doi.org/10.1002/nbm.1134

Halliwell B. (1996): Vitamin C: antioxidant or pro-oxidant in vivo? Free Rad. Res. 25, 439-454 http://dx.doi.org/10.3109/10715769609149066

Harivardhan L. R., Arias J. L., Nicolas J., Couvreur P. (2012): Magnetic nanoparticles: design and characterization, toxicity and biocompatibility, pharmaceutical and biomedical applications. Chem. Rev. 112, 5818-5878 http://dx.doi.org/10.1021/cr300068p

Herbert V., Shaw S., Jayatilleke E. (1996): Vitamin C-driven free radical generation from iron. J. Nutr. 126, S1213-1120

Kohgo Y., Ikuta K, Ohtake T., Torimoto Y., Kato J. (2008): Body iron metabolism and pathophysiology of iron overload. Int. J. Hematol. 88, 7-15 http://dx.doi.org/10.1007/s12185-008-0120-5

Kronick P., Gilpin R. W. (1986): Use of superparamagnetic particles for isolation of cells. J. Biochem. Biophys. Methods $12,73-80$ http://dx.doi.org/10.1016/0165-022X(86)90052-7

Laufberger V. (1937): Sur la cristallisation de la ferritine. Bull. Soc. Chim. Biol. 19, 1575

Lee S., Lee H., Park J., Choi H., Han K., Seo H. (2007): A novel approach to ultrasensitive diagnosis using supramolecular protein nanoparticles. FASEB J. 21, 1324-1234 http://dx.doi.org/10.1096/f.06-7303com

Pankhurst Q., Hautot D., Khan N., Dobson J. (2008): Increased levels of magnetic iron compounds in Alzheimer's disease. J. Alzheimer's Dis. 13, 49-52

Pickard M. R., Chari D. M. (2010): Robust uptake of magnetic nanoparticles (MNPs) by central nervous system (CNS) microglia: Implications for particle uptake in mixed neural cell populations. Int. J. Mol. Sci. 11, 967-981 http://dx.doi.org/10.3390/ijms11030967

Pinkernelle J., Calatayud P., Goya G. F., Fansa H., Keilhoff G. (2012): Magnetic nanoparticles in primary neural cell cultures are mainly taken up by microglia. BMC Neurosci. 13, 32 http://dx.doi.org/10.1186/1471-2202-13-32

Simsek E., Akif Kilic M. (2005): Magic ferritin: A novel chemotherapeutic encapsulation bullet. J. Magn. Magn. Mater. 293, 509-513 http://dx.doi.org/10.1016/j.jmmm.2005.01.066

Singh N., Jenkins G. J. S., Asadi R., Doak S. H. (2010): Potential toxicity of superparamagnetic iron oxide nanoparticles (SPION). Nano Reviews 1, 5358 http://dx.doi.org/10.

Sivoňová M., Žitňanová I., Horáková L., Štrosová M., Muchová J., Balgavý P., Dobrota D., Duračková Z. (2006): The combined effect of pycnogenol with ascorbic acid and trolox on the oxidation of lipids and proteins. Gen. Physiol. Biophys. 25, 379-396

Shukla R. M., Pant R. P. (2003): Kinetic, mechanistic, and thermodynamic investigations on ferrofluid-catalyzed oxidation of L-ascorbic acid by hydrogen peroxide in acidic aqueous solution. J. Colloid Interface Sci. 268, 168-172 http://dx.doi.org/10.1016/S0021-9797(03)00681-7

Takemura Y., Satoh M., Satoh K., Hamada H., Sekido Y., Kubota S. (2010): High dose of ascorbic acid induces cell death in mesothelioma cells. Biochem. Biophys. Res. Commun. 394, 249-253 http://dx.doi.org/10.1016/j.bbrc.2010.02.012

Winterbourn Ch. C. (1995): Toxicity of iron and hydrogen peroxide: the Fenton reaction. Toxicol. Lett. 82-83, 969-974 http://dx.doi.org/10.1016/0378-4274(95)03532-X

Received: September 3, 2012

Final version accepted: February 20, 2013 